\title{
A facile synthesis of potent antiherpes drug substance, Ganciclovir, 9-[(1,3-Dihydroxy-2-propoxy)methyl]guanine, using a new masked glycerol derivative ${ }^{\S}$
}

\author{
V. V. N. K. V. Prasada Raju, ${ }^{\mathrm{a}}$ Vedantham Ravindra, ${ }^{\mathrm{a}}$ Suchitra S. Kamath, ${ }^{\mathrm{a}}$ Vijayavitthal \\ T. Mathad, ${ }^{a}$ Pramod K. Dubey, ${ }^{\text {a }}$ and Padi Pratap Reddy ${ }^{a}$ \\ ${ }^{a}$ Department of Research and Development, Integrated Product Development, Innovation Plaza, \\ Dr. Reddy's Laboratories Ltd., Survey Nos. 42, 45, 46 \& 54, Bachupally, Qutubullapur, R. R. \\ Dist-500 072, Andhra Pradesh, India \\ ${ }^{b}$ Department of Chemistry, Jawaharlal Nehru Technological University, Kukatpally, Hyderabad- \\ 500 072, Andhra Pradesh, India \\ E-mail: prasadvvnkv@drreddys.com
}

\begin{abstract}
A short and facile synthesis of an antiherpes drug substance, ganciclovir is developed using a new masked glycerol derivative as one of the key starting materials.
\end{abstract}

Keywords: Ganciclovir, acyclic nucleoside, antiviral, diacetylguanine, masked glycerol

\section{Introduction}

Ganciclovir $\mathbf{1}$ (Figure 1) is a guanine containing acyclic nucleoside drug (Cytovene, RxList) used to treat infections caused by herpes family viruses and cytomegalovirus. ${ }^{1,2}$ In view of its substantial commercial importance, several synthetic routes were developed for ganciclovir using guanine, ${ }^{3,4}$ acetylguanine, ${ }^{3}$ 2-amino-6-chloropurine, ${ }^{3,5}$ tetraacetylguanosine, ${ }^{6,7}$ and diacetylguanine 2 (Figure 1), ${ }^{8-11}$ as the source of guanine moiety. Coupling of one of such guanine derivatives with an appropriately protected, activated glycerol derivative such as 1,3diacetoxy-2-acetoxymethoxy propane or 1,3-dibenzyloxy-2-acetoxymethoxy propane is the commonly employed strategy to access ganciclovir. 
<smiles>Nc1nc2c(ncn2COC(CO)CO)c(=O)[nH]1</smiles>

1<smiles>O=c1[nH]c(NC2CCCCC2)nc2c1ncn2C(F)(F)F</smiles>

2

Figure 1. Ganciclovir and diacetylguanine.

\section{Results and Discussion}

In our current approach, a new, readily accessible masked glycerol derivative, 2acetoxymethoxy-1,1-diethoxy-3-trityloxypropane $\mathbf{4}$ is used as a source of 1,3-dihydroxy-2propoxymethyl moiety in the synthesis of ganciclovir (Scheme 1). Acetal and trityloxy functions of 4 can be readily transformed into the desired hydroxyls under mild conditions in the final stage of synthetic sequence.

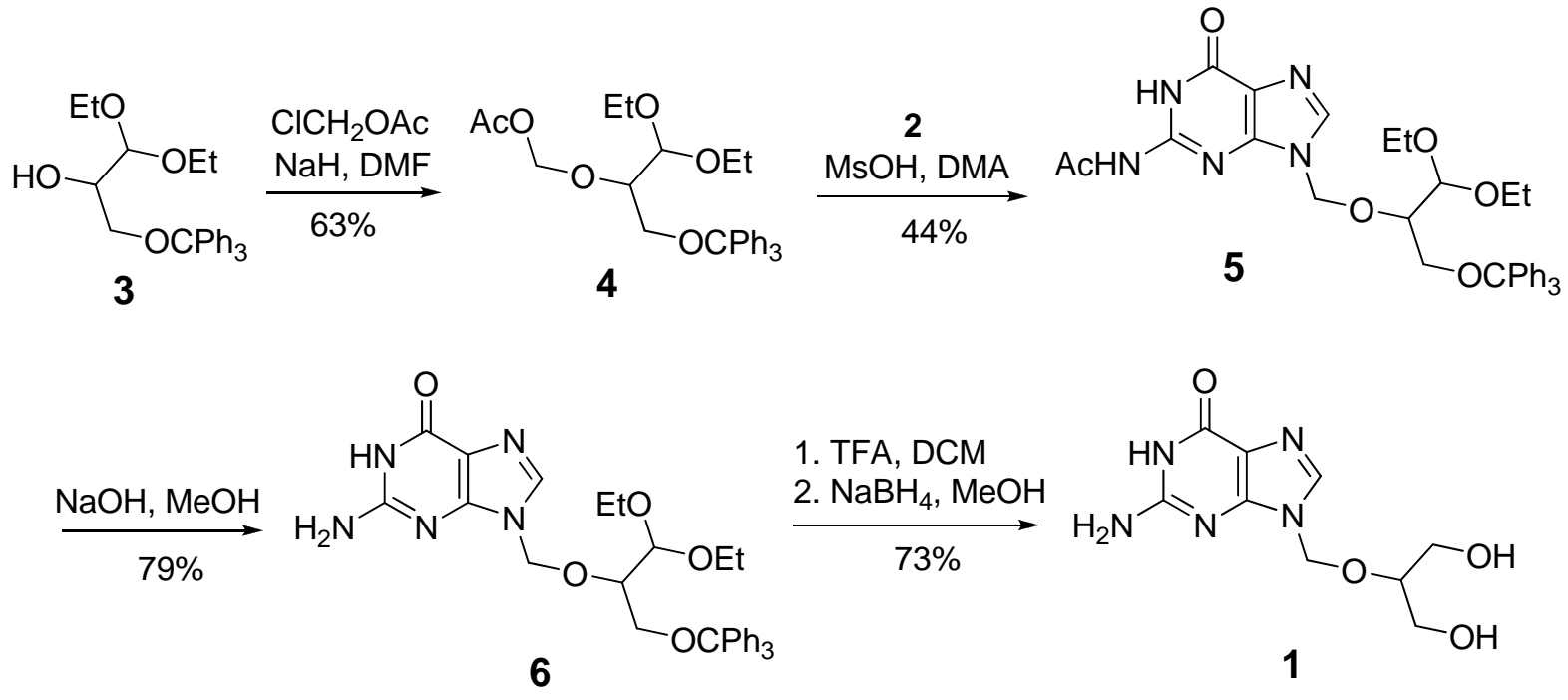

Scheme 1. Synthesis of Ganciclovir.

In the reported processes for the introduction of acetoxymethyl moiety onto the secondary hydroxyl function of appropriate terminal protected glycerol derivatives, a two step protocol involving chloromethylation and subsequent nucleophilic displacement with acetoxy was practiced. $^{8,12}$ We have developed a relatively simple and convenient one step process for functionalizing the secondary hydroxyl to furnish the desired intermediate 4. 
Selective tritylation of the commercially available glyceraldehyde diethyl acetal gave 1,1diethoxy-3-trityloxypropan-2-ol (3). ${ }^{13}$ Reaction of 3 with chloromethyl acetate in the presence of sodium hydride in DMF provided the desired substrate 4 in good yields.

Among several reagent/ solvent combinations (Table 1), NaH/ DMF was proved to be an apt combination to facilitate the conversion of 2-propanol derivative 3 into the desired intermediate 4 (Entry 6, Table 1). The mode of addition of reagents had a tremendous effect on the yield of the reaction. The reaction proceeded with formation of impurities upon successive addition of $\mathrm{NaH}, 3$ and chloromethyl acetate in DMF thereby resulting in low yield of $\mathbf{4}$, the major impurity being the acetyl derivative of $\mathbf{3}$. The yield drastically increased by first activation of $\mathbf{3}$ using $\mathrm{NaH}$ followed by dropwise addition of this activated $\mathbf{3}$ to chloromethyl acetate in DMF.

Table 1. Reagent/ solvent combinations for conversion of 2-propanol derivative 3 to 4

\begin{tabular}{cccc}
\hline Entry & Base & Solvent & Yield (\%) \\
\hline 1 & $\mathrm{~K}_{2} \mathrm{CO}_{3}$ & Acetone & 0 \\
2 & $\mathrm{~K}_{2} \mathrm{CO}_{3}$ & DCM & 0 \\
3 & $\mathrm{~K}_{2} \mathrm{CO}_{3}, \mathrm{NaI}$ & Acetone & 4 \\
4 & $\mathrm{DMAP}$ & $\mathrm{DCM}$ & 0 \\
5 & $\mathrm{KOH}$ & $\mathrm{DMF}$ & 9 \\
6 & $\mathrm{NaH}$ & $\mathrm{DMF}$ & 63 \\
7 & $\mathrm{NaH}$ & Toluene & 49 \\
8 & $\mathrm{NaH}$ & $\mathrm{THF}$ & 52 \\
9 & $\mathrm{NaH}$ & DMSO & 45 \\
\hline
\end{tabular}

Such a one step chloromethylation of secondary hydroxyl function to get similar structural motif was hither to be unknown in the literature.

Reaction of $\mathbf{4}$ with diacetylguanine $\mathbf{2}$ was conducted in dimethylacetamide in the presence of methanesulfonic acid to give 5 (44\%). The acetamido guanine derivative 5 could be smoothly transformed into its corresponding amino derivative 6 (79\%) on alkaline hydrolysis in methanol. The preparation of $\mathbf{5}$ and $\mathbf{6}$ were done by following the similar procedure reported in literature. ${ }^{10}$ Concomitant deprotection of acetal and trityl functions of $\mathbf{6}$ using TFA in DCM and subsequent reduction of the aldehyde derivative using $\mathrm{NaBH}_{4}$ in the same pot directly furnished ganciclovir 1 (73\%). The formation of $\mathbf{1}$ (16\% when calculated from 3) was confirmed by comparison of analytical data with that of authentic compound reported in literature. ${ }^{8}$

\section{Conclusions}

In conclusion, readily accessible substrates, relatively mild reaction conditions and simple inexpensive deprotection operations render our approach to ganciclovir attractive. Further 
application of this synthetic protocol in the synthesis of structurally similar and commercially important antiviral active pharmaceutical ingredients is under exploration.

\section{Experimental Section}

General. IR spectra were recorded in the solid state as a $\mathrm{KBr}$ dispersion using a Perkin-Elmer FT-IR spectrophotometer. ${ }^{1} \mathrm{H}$ NMR spectra were scanned in DMSO- $d_{6}$ on a Mercury Plus spectrometer with TMS as an internal standard. HR-MS spectra were obtained on Waters LCT Premier XE (Micro mass Oa-TOF) instrument. The solvents and reagents were used without any purification.

Preparation of 2-acetoxymethoxy-1,1-diethoxy-3-trityloxypropane (4). To a solution of $\mathrm{NaH}$ (144 mg, $6 \mathrm{mmol})$ in anhydrous DMF $(25 \mathrm{~mL})$ was added 1,1-diethoxy-3-trityloxypropan-2-ol $3^{13}$ (4.06 g, $10 \mathrm{mmol}$ ) at room temperature and reaction mixture was stirred for $10 \mathrm{~h}$ under $\mathrm{N}_{2}$. This solution was added dropwise at regular intervals to a cooled solution of chloromethyl acetate $(1.0 \mathrm{~mL}, 10 \mathrm{mmol})$ in DMF $(25 \mathrm{~mL})$ at $15-20^{\circ} \mathrm{C}$. The reaction mixture was stirred for 5-6 $\mathrm{h}$, quenched with chilled water and extracted with diisopropyl ether. The ether layer was dried over sodium sulfate and concentrated under vacuum to give crude compound $\mathbf{4}$ as a residue, which was purified by column chromatography eluting with $10 \% \mathrm{MeOH}$ in EtOAc; yield: $3 \mathrm{~g}$ (63\%); IR (KBr): 3444, 3086, 3059, 2974, 2874, 1747, 1649, 1490, 1448, 1227, 1154, 1066, $1012,947,704 \mathrm{~cm}^{-1} ;{ }^{1} \mathrm{H}$ NMR $\left(400 \mathrm{MHz}, \mathrm{Me}_{2} \mathrm{SO}-d_{6}\right): \delta=7.46-7.42(\mathrm{~m}, 6 \mathrm{H}), 7.30-7.20(\mathrm{~m}, 9 \mathrm{H})$, $4.53(\mathrm{~d}, J=6.3 \mathrm{~Hz}, 1 \mathrm{H}), 4.29(\mathrm{~s}, 2 \mathrm{H}), 3.81-3.77(\mathrm{~m}, 1 \mathrm{H}), 3.60-3.54(\mathrm{~m}, 2 \mathrm{H}), 3.33-3.29(\mathrm{~m}, 2 \mathrm{H})$, 3.23-3.18 (m, 2H), $2.01(\mathrm{~s}, 3 \mathrm{H}), 1.00(\mathrm{t}, 3 \mathrm{H}), 0.86(\mathrm{t}, 3 \mathrm{H})$; HRMS for $\mathrm{C}_{29} \mathrm{H}_{34} \mathrm{O}_{6}[\mathrm{M}+\mathrm{H}]^{+}: \mathrm{m} / \mathrm{z}$ Calcd: 479.2699; Found: 479.2702.

Preparation of $N^{2}$-acetyl-9-[(1,1-diethoxy-3-trityloxy-2-propoxy)methyl]guanine (5). To a solution of diacetylguanine 2 (1.41 g, $6 \mathrm{mmol}$ ) and 2-acetoxymethoxy-1,1-diethoxy-3trityloxypropane $4(2.9 \mathrm{~g}, 6 \mathrm{mmol})$ in dimethylacetamide $(30 \mathrm{~mL})$ was added methanesulfonic acid $(0.1 \mathrm{~mL}, 1.2 \mathrm{mmol})$ at room temperature. The reaction mixture was heated at $75-80{ }^{\circ} \mathrm{C}$ for 20-21 h, cooled to room temperature and extracted with DCM. The DCM layer was dried over sodium sulfate and concentrated under vacuum to give crude compound 5 , which was purified by column chromatography eluting with $4 \% \mathrm{MeOH}$ in $\mathrm{CHCl}_{3}$; yield: $1.6 \mathrm{~g}(44 \%)$; IR (KBr): 3120 , 3054, 2927, 2855, 1692, 1617, 1547, 1449, 1373, 1265, 1083, 1062, 896, $738 \mathrm{~cm}^{-1}$; ${ }^{1} \mathrm{H}$ NMR $\left(400 \mathrm{MHz}, \mathrm{Me}_{2} \mathrm{SO}-d_{6}\right): \delta=12.15(\mathrm{~s}, 1 \mathrm{H}), 11.63(\mathrm{~s}, 1 \mathrm{H}), 8.46(\mathrm{~s}, 1 \mathrm{H}), 7.28-7.19(\mathrm{~m}, 15 \mathrm{H}), 5.8(\mathrm{~s}$, 2H), $4.38(\mathrm{~d}, J=6.1 \mathrm{~Hz}, 1 \mathrm{H}), 4.03-3.99(\mathrm{~m}, 1 \mathrm{H}), 3.57-3.37(\mathrm{~m}, 4 \mathrm{H}), 2.93-2.89(\mathrm{~m}, 2 \mathrm{H}), 2.16$ (s, $3 \mathrm{H}), 0.86(\mathrm{t}, 3 \mathrm{H}), 0.83(\mathrm{t}, 3 \mathrm{H})$; HRMS for $\mathrm{C}_{34} \mathrm{H}_{37} \mathrm{~N}_{5} \mathrm{O}_{6}[\mathrm{M}+\mathrm{H}]^{+}: \mathrm{m} / \mathrm{z}$ Calcd: 612.2822; Found: 612.2835 .

Preparation of 9-[(1,1-diethoxy-3-trityloxy-2-propoxy)methyl]guanine (6). A solution of compound 5 (1.83 g, $3 \mathrm{mmol})$ and $\mathrm{NaOH}(0.12 \mathrm{~g}, 3 \mathrm{mmol})$ in $\mathrm{MeOH}(15 \mathrm{~mL})$ was stirred at 40$50{ }^{\circ} \mathrm{C}$ for 3-4 h. The reaction mixture was cooled to room temperature and extracted with EtOAc. 
The organic extract was dried over sodium sulfate and concentrated under vacuum to give compound 6; yield: $1.35 \mathrm{~g}$ (79\%); IR (KBr): 3321, 3167, 3059, 3033, 2973, 2928, 1685, 1560, 1475, 1448, 1377,1213, $1089 \mathrm{~cm}^{-1}$; ${ }^{1} \mathrm{H}$ NMR $\left(400 \mathrm{MHz}, \mathrm{Me}_{2} \mathrm{SO}-d_{6}\right): \delta=10.82(\mathrm{~s}, 1 \mathrm{H}), 8.17(\mathrm{~s}$, $1 \mathrm{H}), 7.43-7.20(\mathrm{~m}, 15 \mathrm{H}), 6.15(\mathrm{~s}, 2 \mathrm{H}), 5.75(\mathrm{~s}, 2 \mathrm{H}), 4.36(\mathrm{~d}, J=5.9 \mathrm{~Hz}, 1 \mathrm{H}), 4.01-3.98(\mathrm{~m}, 1 \mathrm{H})$, 3.54-3.43 (m, 4H), 2.94-2.88 (m, 2H), $1.01(\mathrm{t}, 3 \mathrm{H}), 0.86(\mathrm{t}, 3 \mathrm{H})$; HRMS for $\mathrm{C}_{32} \mathrm{H}_{35} \mathrm{~N}_{5} \mathrm{O}_{5}[\mathrm{M}+\mathrm{H}]^{+}$: m/z Calcd: 570.2716; Found: 570.2728.

Preparation of ganciclovir (1). A mixture of compound $6(569 \mathrm{mg}, 1 \mathrm{mmol})$ and TFA $(0.3 \mathrm{~mL}$, $4 \mathrm{mmol})$ in DCM $(10 \mathrm{~mL})$ was stirred at room temperature for $4 \mathrm{~h}$. The solvent was stripped off under reduced pressure and $\mathrm{MeOH}(20 \mathrm{~mL})$ was added to the residue and the solution was stirred at $10-15^{\circ} \mathrm{C}$. Sodium borohydride $(45.6 \mathrm{mg}, 1.2 \mathrm{mmol}$ ) was added in portions and the mixture was stirred for $2 \mathrm{~h}$ at $25^{\circ} \mathrm{C}$. The reaction mixture was poured into cold water, the solid obtained was filtered and recrystallized from $\mathrm{MeOH}$ to give ganciclovir as a white solid; yield: $186 \mathrm{mg}$ (73\%); mp 248-250 우 IR (KBr): 3420, 3320, 3159, 3101, 2942, 2892, 1687, 1658, 1491, 1475, 1367, 1064, $1045 \mathrm{~cm}^{-1}$; ${ }^{1} \mathrm{H}$ NMR (400 MHz, Me $\left.2 \mathrm{SO}-d_{6}\right): 10.62$ (s, $\left.1 \mathrm{H}\right), 7.796$ (s, $\left.1 \mathrm{H}\right), 6.47$ (s, 2 $\mathrm{H}), 5.43(\mathrm{~s}, 2 \mathrm{H}), 4.62(\mathrm{t}, 2 \mathrm{H}), 3.53(\mathrm{~m}, 1 \mathrm{H}), 3.30-3.52(\mathrm{~m}, 4 \mathrm{H})$.

\section{Acknowledgements}

We thank the management of the Dr. Reddy's Laboratories Ltd., for supporting this work. Cooperation from the colleagues from analytical research and development is highly appreciated.

\section{References}

${ }^{\S}$ Dr. Reddy's Communication no. IPDO IPM-00177

1. Fan-Havard, P.; Nahata, M. C.; Brady, M. T. J. Clin. Pharm. Therap. 1989, 14, 329.

2. Faulds, D.; Heel, R.C. Drugs 1990, 39, 597.

3. Ogilvie, K. K.; Cheriyan, U. O.; Radatus, B. K.; Smith, K. O.; Galloway, K. S.; Kennell, W. L. Can. J. Chem. 1982, 60, 3005.

4. Hakimelahi, G. H.; Khalafi-Nezhad, A. Helv. Chim. Acta 1989, 72, 1495.

5. Ogilvie, K. K.; Hanna, H. R.; Proba, Z. Nucleosides Nucleotides 1986, 5, 169.

6. Boryski, J.; Golankiewicz, B. Nucleosides Nucleotides 1989, 8, 529.

7. Boryski, J.; Golankiewicz, B. Synthesis 1999, 625.

8. Martin, J. C.; Dvorak, C. A.; Smee, D. F.; Matthews, T. R.; Verheyden, J. P. H. J. Med. Chem. 1983, 26, 759.

9. Mcgee, D. P. C.; Martin, J. C.; Verheyden, J. P. H. Synth. Commun. 1988, 18, 1651.

10. Ashton, W. A.; Karkas, J. D.; Field, A. K.; Tolman, R. L. Biochem. Biophys. Res. Commun. 1982, 108, 1716. 
11. Field, A. K.; Davies, M. E.; Dewitt, C.; Perry, H. C.; Liout, R.; Germershausen, J.; Karkas, J. D.; Ashton, W. T.; Johnston, D. B. R.; Tolman R. L. Proc. Natl. Acad. Sci. USA 1983, 80, 4139.

12. Martin, J. C.; McGee, D. P. C.; Jeffrey, G. A.; Hobbs, D. W.; Smee, D. F.; Matthews, T. R.; Verheyden, J. P. H. J. Med. Chem. 1986, 29, 1384.

13. Angrick, M.; Rewicki, D. Liebigs Ann. Chem. 1982, 2, 366. 